\title{
Heavy metals in the organic soil horizon of the Northern taiga forests resulting from industrial air pollution
}

\author{
Alexander Evdokimov* \\ Herzen State Pedagogical University of Russia, 48 Moika River Emb., Saint Petersburg 191186, \\ Russia
}

\begin{abstract}
This study focuses on heavy metals contained in organic soil horizons resulting from the industrial air pollution caused by local enterprises. Polymetallic dust containing heavy metals is one of the main by-products in the smelting of non-ferrous metals. We evaluated the contents of $\mathrm{Ni}, \mathrm{Cu}$, and $\mathrm{Co}$ in the upper soil horizons containing the maximum amount of these pollutants (due to the formation of stable compounds with organic components of these horizons). Sampling was carried out at various distances from the source of pollution at previously established test sites. The study found acid-soluble heavy metals at various distances from the source of pollution and revealed the regularity of their content, both qualitative and quantitative.
\end{abstract}

\section{Introduction}

The Kola Peninsula features tundra and forest podzolic soils. These soils are marked by low productivity with little organic matter arriving with litter every year. Organic matter is concentrated in the uppermost part of the soil profile, where the root systems of plants are found. Unfavourable temperature conditions, low ash content of litter and poor soil aeration, adversely affect the microbial activity resulting in insufficient humus content [1]. Another feature of such soils is pronounced gleying. The surface horizons of podzolic soils are depleted in nutrients especially highly-soluble compounds of potassium, phosphorus, and nitrogen. These soils are among the most unsaturated and acidic soils in the world. They are infertile due to their high acidity, low nutrient content, the prevalence of brown humus and poor water physical properties [2].

The vitality of plants growing in the area with industrial air pollution is affected by substances that penetrate the plant not only through its assimilation system, but also through its underground organs along with water [3]. The ability of soil to accumulate these substances is central to our study as it focuses on heavy metals-primarily nickel, copper and cobalt-contained in the soil in soluble and metabolic forms $[4,5]$.

\footnotetext{
* Corresponding author: evdokimov89@gmail.com
} 
The study aims to compare the quantitative content of heavy metals (nickel, copper, and cobalt) in the organic soil horizons in common pine communities located in the areas of Northern Taiga affected by industrial air pollution.

\section{Materials and methods}

The evidence for the study was obtained on the Kola Peninsula in Monchegorsky (buffer and impact zones), Kovdorsky and Olenegorsky districts (non-contaminated area) at previously established test sites located at different distances from the source of pollution (the Severonickel plant) (Fig. 1). These sample plots are located in middle-aged pine forests (Pinus sylvestris L.) with disturbance of about 80 years and undergoing regular aerotechnogenic impact. Samples of the upper organic horizon of the Al-Fe podzolic soil were taken from each test area with the subsequent exclusion of undecomposed upper level of forest litter large inclusion, living components (roots) and large mineral components of the parent materials (stones) (in the number of 5 samples for each sample plot) [6]. These samples were used to prepare a soil extract (extraction with a $\mathrm{HCl}$ solution of $1.0 \mathrm{n}$ ). At the next stage, atomic absorption spectrometry was used to determine the content of acidsoluble forms of $\mathrm{Ni}, \mathrm{Cu}$, and $\mathrm{Co}$. The paper presents the average values of the available sample for these sample plots.

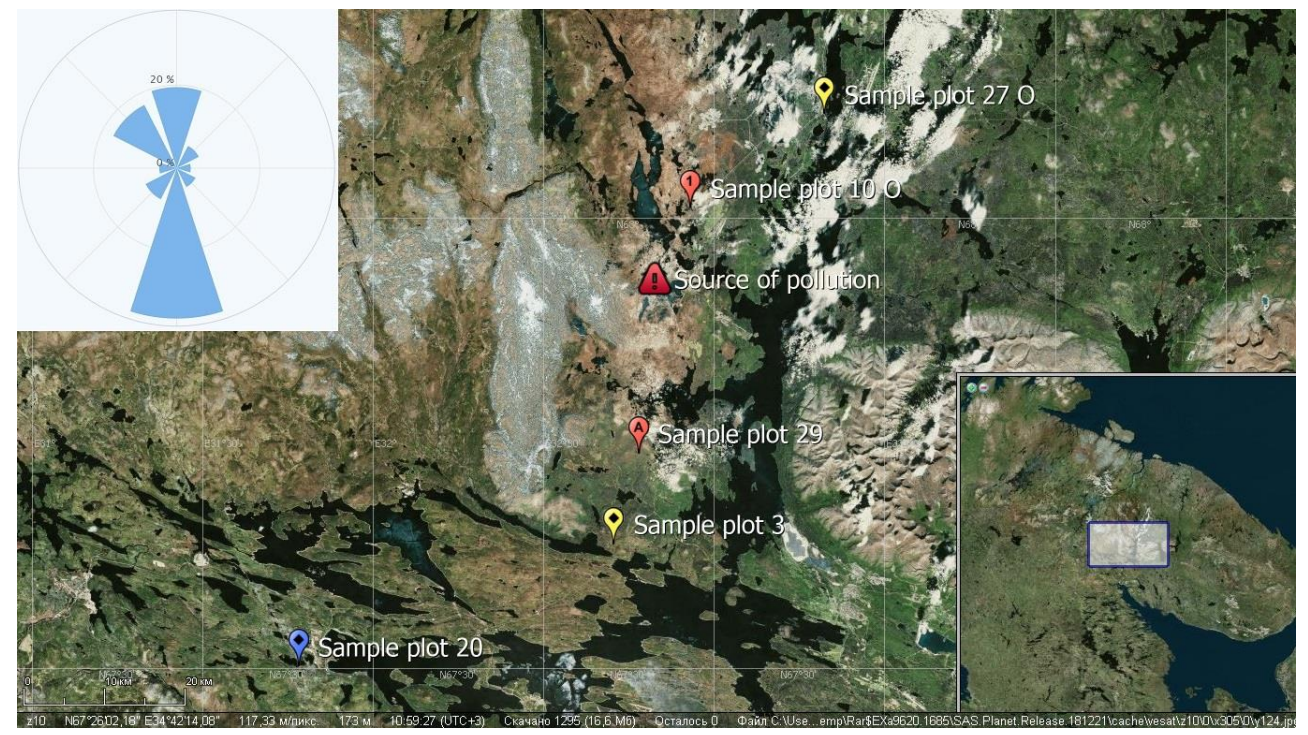

Fig. 1. Sample plots location map

Also, for these sample plots, the technogenic load index $\left(\mathrm{I}_{\mathrm{I}}\right)$ was calculated, which is the ratio of the current pollution level (total or for each individual pollutant) to the noncontaminated indicator for this region. This index is a generally accepted indicator for assessing the technogenic load of the territories of a given region and is actively used by the staff of the laboratories performing this assessment (including the staff of the Laboratory of Plant Ecology of Komarov Botanical Institute of the Russian Academy of Sciences). This index can be represented as a formula (1):

$$
I_{I}=P / C,
$$

where $I_{I}$ - technogenic load index; $P$ - pollutant content; $C$ - pollutant content in the noncontaminated area. 
The indicator is widely used in assessing the technogenic impact on ecosystems and their components and allows us to determine how many times the pollutant content (in this case, heavy metals) exceeds similar indicators in an unpolluted region. The background values are taken as an indicator of the content of heavy metals of those territories of a given region that are not subject to aerotechnogenic emission of any sources.

\section{Results}

The study showed that the average content of nickel, copper, and cobalt in noncontaminated areas is $7.5 \mathrm{mg} / \mathrm{kg}, 16.75 \mathrm{mg} / \mathrm{kg}$, and $1.5 \mathrm{mg} / \mathrm{kg}$ respectively. Recent studies [7] report $10 \mathrm{mg} / \mathrm{kg}$ of nickel and copper in non-contaminated areas (which corresponds to the "normal" content of heavy metals for soils in this region that do not have the influence of aerotechnogenic emission of these substances). Thus, there is a slight increase in the copper content most likely due to the location of non-contaminated sample plots relative to the prevailing winds (south of the plant). Another possible reason is changes in the plant production practices (the use of various ores, new methods of production and refining, etc.). The cobalt content does not exceed the threshold for non-contaminated areas.

In the buffer zone, the nickel content is about $50 \mathrm{mg} / \mathrm{kg}$, which is 5 times higher than the values in non-contaminated areas. The copper content ranges from 185.5 to $76.9 \mathrm{mg} / \mathrm{kg}$ (different test areas), whereas the cobalt values range from 2.72 to $5.63 \mathrm{mg} / \mathrm{kg}$, which also significantly exceeds the values for non-contaminated areas.

The impact zones show much higher concentrations of the three metals reaching as much as $598.5 \mathrm{mg} / \mathrm{kg}$ (60 times higher) for nickel, 3,582 mg/kg (almost 360 times higher) for copper, and $28.7 \mathrm{mg} / \mathrm{kg}$ (almost 20 times higher) for cobalt (Fig. 2) (Table 1).

Table 1. The values of the content of heavy metals in the organic soil horizon at different distances from the source of pollution

\begin{tabular}{|c|c|c|c|c|}
\hline \multirow{2}{*}{ Study area } & \multirow{2}{*}{$\begin{array}{c}\text { Distance from } \\
\text { the source of } \\
\text { pollution, } \mathbf{k m}\end{array}$} & \multicolumn{3}{|c|}{ Content in the soil, mg / kg } \\
\cline { 3 - 5 } & 65 & $\mathrm{Ni}$ & $\mathrm{Cu}$ & $\mathrm{Co}$ \\
\hline Non-contaminated & 35 & 69.10 & 18.75 & 1.46 \\
\hline \multirow{3}{*}{ Buffer } & 25 & 45.45 & 76.99 & 2.72 \\
\cline { 2 - 5 } & 15 & 510.75 & 2182.15 & 5.63 \\
\hline \multirow{3}{*}{ Impact } & 15 & 434.58 & 2034.20 & 16.70 \\
\cline { 2 - 5 } & 10 & 598.52 & 3582.00 & 28.68 \\
\cline { 2 - 5 } & & & & \\
\hline
\end{tabular}

The general index of technogenic load also varies greatly depending on the approach to the source of pollution. As mentioned earlier, in an area not experiencing an aerotechnogenic load, this indicator is 1 . In the buffer zone, the total value of this index (for all three pollutants) is 9.5 (for the trial area south of the pollution source) and 4.7 (for the trial area north of the source of pollution). On average, this figure is 7.1. In the impact zone, this indicator is 91.4 (for the trial area south of the pollution source) and 125.5 (for the trial area north of the pollution source). The average for the impact zone is 108.5 (Fig. 3). 


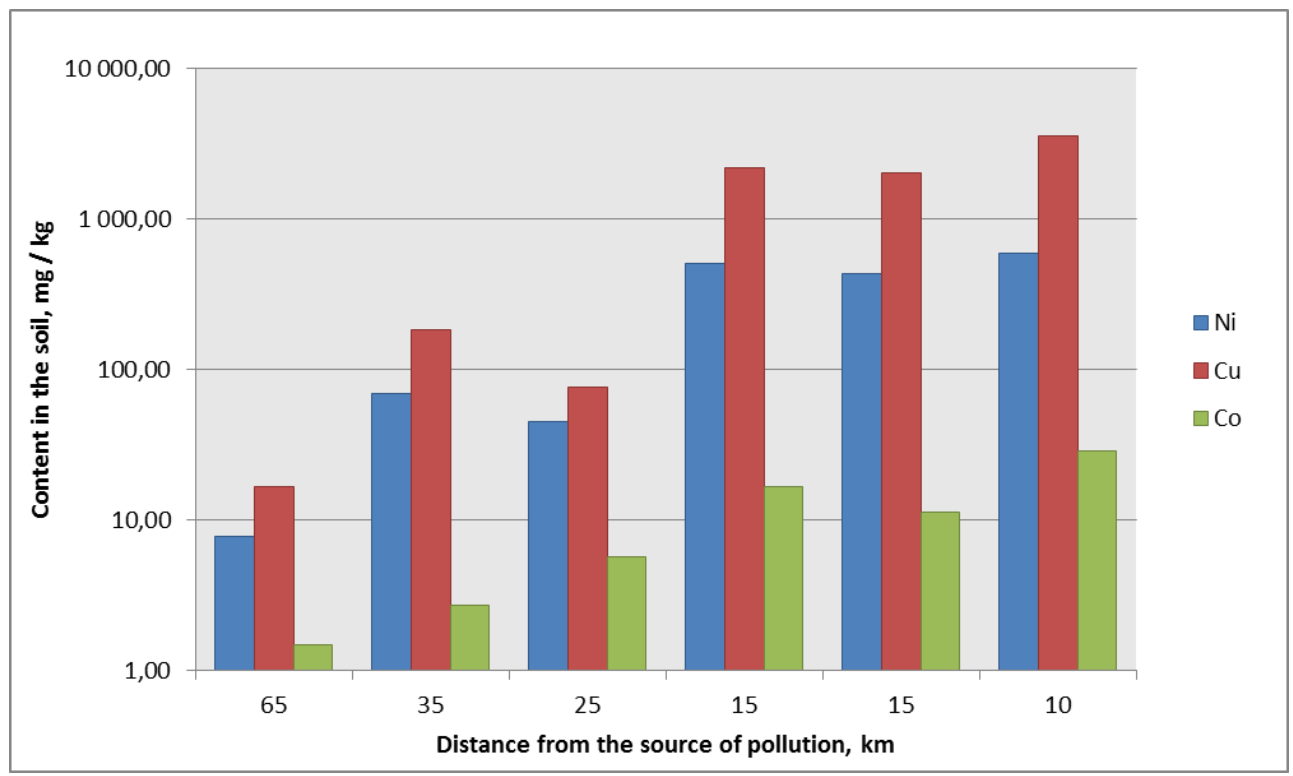

Fig. 2. The content of heavy metals in the organic soil horizon at different distances from the source of pollution (logarithmic scale of ordinates)

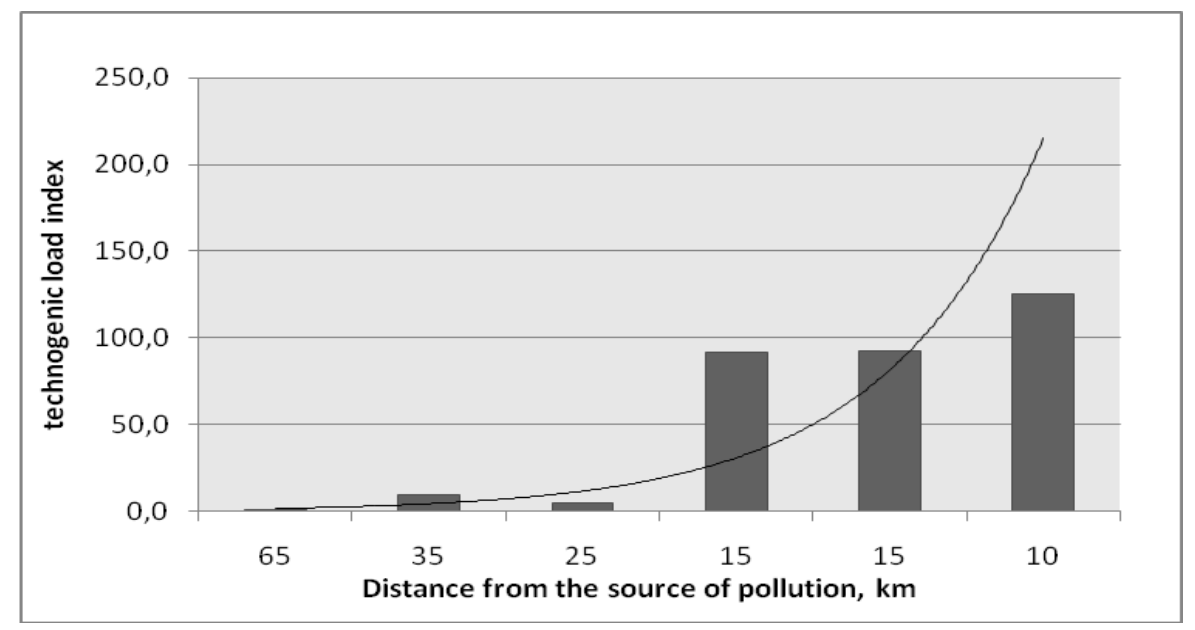

Fig. 3. The technogenic load index of the organic soil horizon at different distances from the source of pollution

As can be seen from the histogram, the content of heavy metals varies progressively depending on the distance to the source of pollution (for this reason the logarithmic scale of ordinates was used). Moreover, this is true for each of the three heavy metals despite a huge differenece in values. Thus, we observe a pattern characteristic of this region as well as other similar places.

An increase in the technogenic load index also occurs progressively in accordance with the exponential curve. On average, in the buffer zone $(25-35 \mathrm{~km})$, the content of heavy metals exceeds background values by more than 7 times. For the impact zone $(10-15 \mathrm{~km})$, the increase in this indicator is even more noticeable. The content of heavy metals on average for this territory exceeds background values by more than 108 times. 


\section{Conclusion}

The content of heavy metals in the organic soil horizon varies progressively (the content of heavy metals in the soil increases exponentially) depending on the proximity to the source of pollution. The content of heavy metals in different components of the community on average exceeds that for the non-contaminated area by 1.5-2 times and 2-15 times in the buffer and impact zones respectively. Regarding the impact zone, it can be assumed that the marked excess of heavy metals (primarily copper) is associated with the accumulation of these substances in the soil. It occurs primarily in organic horizons due to the formation of stable complexes with organic molecules (chilates), which prevent the active leaching of these substances into mineral horizons with precipitation.

There are noticeable differences in the content of each of the three components at any distance from the source of pollution (the content of copper and nickel is on average several times higher than that of cobalt). This can be explained by the nature of the ores used in the enterprise. Namely, the plant focuses on the smelting of copper and nickel. Cobalt is a side component of these ores, which explains such noticeable differences.

\section{References}

1. N. P. Belov, A. V. Baranovskaya, Soils of the Murmansk region. (JL: Science, 1969)

2. M. A. Glazovskaya, A. N. Gennadiev, Soil geography with the basics of soil science. (Moscow State University, Moscow, 1995)

3. I. V. Lyanguzova, Russian Journal of Ecology, 48, 4 (2017)

4. I. V. Lyanguzova, V.T. Yarmishko, A.S. Evdokimov, A.I. Belyaeva, Plant resources, 54, 4 (2018)

5. V. S. Barkan, I. V. Lyanguzova, Eurasian Soil Science, 51, 3 (2018)

6. E. L. Vorobeichik, S. Y. Kaigorodova, Eurasian Soil Science, 50, 8 (2017)

7. V. T. Yarmishko, I. V. Lyanguzova, M. A. Yarmishko, Agrarian Russia, 2, (2009) 